\title{
FACTORS INFLUENCING HIV KNOWLEDGE AMONG WOMEN OF CHILDBEARING AGE IN SOUTH SUMATRA, INDONESIA
}

\author{
Najmah $^{1,5}$ *, Indah Purnama Sari ${ }^{2}$, Tri Novia Kumalasari ${ }^{3}$, Sharyn Graham Davies ${ }^{4}$ and Sari Andajani $^{5}$ \\ ${ }^{1}$ Epidemiology Department, Public Health Faculty, Sriwijaya University, Indonesia \\ ${ }^{2}$ Biostatistics Department, Public Health Faculty, Sriwijaya University, Indonesia \\ ${ }^{3}$ Epidemiology Department, Public Health Faculty, Sriwijaya University, Indonesia \\ ${ }^{4}$ Faculty of Social Science, Auckland University of Technology, ${ }^{5}$ Faculty of Health and Environmental Science, \\ Auckland University of Technology
}

* Corresponding Author: Najmah,

E-mail: najem240783@yahoo.com/sari.andajani@aut.ac.nz

\begin{abstract}
This study aims to provide detailed information on the role of the following social determinants (i.e. education, occupation, place of residence, marital and economic status) in the acquisition of HIV knowledge among women of childbearing age (15-49 years old). The study uses secondary data from the 2012 Indonesian Demographic and Health Survey (IDHS). The IDHS used a quantitative analytical approach with a cross-sectional study design and multi-stage stratified sampling. The sample included 1,335 women aged 15 to 49 years old living in South Sumatra Province, Indonesia. Descriptive analysis, ANOVA, and t-test and multiple logistic regressions were performed in this study. The results show one out of two women have little HIV knowledge. The more highly educated women were positively associated with a greater degree of knowledge related to comprehensive knowledge related to HIV (AOR: 3.7, 2.2-6.2, p. $<0.05)$, HIV prevention (AOR:16.6, 1.8-153.9, $p<0.05)$, transmission from mother to child (AOR:11.1, 3.3-36.9, $p$ $<0.05)$, HIV misconceptions (AOR:5.1, 1.1-23.1, $p<0.05)$ and HIV services (AOR:5.7, 2.8-11.4, $p<0.05)$. In addition, the women lived in urban areas had more knowledge related to HIV prevention and transmission (AOR: 3.36, 1.8-6.2, $p$ $<0.05)$, and knowledge about mother-to-child of HIV transmission (AOR: 3.2, 1.8-5.5, $p<0.05)$ compared to those who lived in rural areas. To conclude, education level was found to be the dominant factor associated with knowledge of HIV across all categories of knowledge after controlling by other determinants, age, marital status, working status and residence. HIV awareness and comprehensive HIV information among women who are considered to be in a low-risk group for HIV infection should be integrated with formal education as well as in maternal health services, particularly in rural areas.
\end{abstract}

Keywords: HIVIAIDS, Knowledge, Women of Childbearing Age, IDHS 2012

\section{INTRODUCTION}

About $40 \%$ of all new HIV-positive cases in the last ten years in Indonesia were found among women. Based on a $2018 \mathrm{MOH}$ report, there is a rapid increase of reported cases in the last 10 years amongst women aged 15-49 years from 3,565 HIV cases in 2008, to 9,318 cases in 2012. In 2017, the number of new HIV cases among woman increased fivefold to 17,579 (1). The number of HIV-positive pregnant women is predicted to increase from 15,517 or $0.38 \%$ of all pregnancies to nearly 20,000 cases ( $0.49 \%$ of pregnancies) between 2012

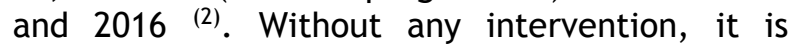
predicted around 8,604 babies born with HIV will cost 42 billion Rupiah to care for annually (3). Unfortunately, previous studies have found HIVpositive mothers in Indonesia typically find out about their HIV status long after they become infected, often when their children or husband becomes ill due to HIV/AIDS or when they are asked for a blood test during pregnancy ${ }^{(4-6)}$.

Social determinants of women's vulnerability to HIV include a range of social, economic and environmental factors, such as income, social status, education, violence, and sexual and cultural norms ${ }^{(7-11)}$. Previous studies in Indonesia by Angkasawati and Arifin (2010), Iswanto (2011), and Pradnyani, Wibowo and Mahmudah (2019) using the 2007 National Basic Health Research (NBHR) and 2007 and 2012 Indonesian Demographic and Health Survey (IDHS), proposed the following social determinants of HIV knowledge among women of childbearing age: education, marriage status, type of residence, working status and wealth (12-14). Following those studies, the 2010 NBHR and the 2012 IDHS indicated that only $11.4 \%$ of the total of 91,433 women respondents and $12 \%$ of total of of 45,607 women surveyed respectively had comprehensive HIV/AIDS knowledge across 33 provinces ${ }^{(15,16),}$, an important determinant in HIV vulnerability. Nevertheless, the decentralisation out of 34 provinces in Indonesia provides a space for each province in Indonesia to determine their health needs based on the local context ${ }^{(17)}$. The social determinants that are associated with HIV literacy among women of childbearing age (15-49 years old) therefore urgently need to be understood, specifically to low prevalence province in Indonesia, such as, South Sumatra, the research interest setting, with Strong Malay culture and Islamic teachings. 
This article aims to provide detailed information on the roles of the following social determinants, namely, education level, occupation, residence, marital status, wealth index and age in the HIV knowledge acquisition among women of childbearing age in South Sumatra province of Indonesia. It draws data from the 2012 IDHS study. The level of HIV knowledge is divided into five parts: 1) comprehensive knowledge of HIV; 2) HIV prevention; 3) HIV misconceptions; 4) HIV transmission; and 5) HIV services. Findings from this article will contribute to the in-depth understanding of different levels of knowledge of HIV transmission, prevention, services, and misconceptions which can provide a framework for cost-effective and well-targeted health promotion relevant to specific social determinants and levels of HIV knowledge.

\section{METHODOLOGY}

\section{Population, Sampling and Sample}

This article utilises existing secondary data from IDHS-2012, which used a cross-sectional study design and multistage stratified sampling. Furthermore, to attain more accurate conclusions, complex sample design for this multistage sampling was used from the 2012 IDHS. The South Sumatra sample was selected for our analysis and it included 1,355 women aged 15-49 years.

\section{Data Collection}

The survey questions used in the IDHS-2012 included knowledge about HIV/AIDS and variables related to selected social determinants, such as education level, occupation, residence, marital status, and age of women and their partners. Some variables were recoded including marital status, type of residence, education level and wealth index. All South Sumatra samples from the IDHS-2012 report were included in the data analysis. Three missing data were recoded into 'not known'.

\section{Ethical Considerations}

Ethical approval for this study was obtained from the Ethics Committee of Medical Faculty of Sriwijaya University (No. $173 /$ keprsmhfkunsri/2016). DHS is open sources data that can be accessed in http://dhsprogram.com/. DHS for Indonesia can be downloaded in http://dhsprogram.com/data/dataset/Indonesia Special_2012.cfm?flag=0.

\section{Data Analysis}

Preliminary analysis was run using univariate analysis to examine the statistical properties (i.e. frequency, mean, max, min, standard deviation, or normal distribution of a particular variable). Mean and standard deviation are reported for numerical data, such as age, and frequency and proportion are reported for categorical variables, like questions of knowledge related to HIV and other variables related to the social determinants.

Table 1 Stratification of Knowledge Related to HIV

Stratification of knowledge related to HIV

\begin{tabular}{cl}
\hline Indicator 1. & $\begin{array}{l}\text { Comprehensive knowledge relate } \\
\text { to HIV } \\
\text { Knowledge of HIV } \\
\text { prevention/transmission } \\
\text { Knowledge of HIV misconceptions }\end{array}$ Indicator 3. \\
Indicator 4. & $\begin{array}{l}\text { Knowledge of mother-to-child } \\
\text { transmission (MTCT) } \\
\text { Indicator 5. }\end{array}$
\end{tabular}

\section{Questions in IDHS-2012}

All questions from indicator 2-4

Limiting numbers of sex partners, condom use and not using shared needle and syringe.

Whether HIV is transmitted through mosquito bites, eating together with HIV positive person, supernatural power", and signs of people with HIV Whether HIV can be transmitted through pregnancy, delivery and breastfeeding

HIV test can be done by a blood test and whether they knew about voluntarily HIV/AIDS test and counselling (VCT) services

Note: Adapted from Angkasawati (2007), Husseini and Abu-Rmeilah (2007), Yaya et al (2016), Pradnyani et.al (2019), Zainiddinov and Habibov (2016) $(12,14,18-20)$

\section{Definition}

Questions related to knowledge of HIV were stratified based on previous studies ${ }^{7,1011,12}$. All questions in each category were scored " 2 " for a correct answer; "1" for an incorrect answer; and "0"for a 'do not know' answer and then calculated as total scores for each stratification. ANOVA and independent-sample-test with 5\% significance levels of alpha were performed to examine a mean difference in the total score of HIV knowledge across all social determinants. The results of the univariate analysis are presented in Tables 1 and 2, and bivariate analysis in Table 3. Then, a multiple logistic was performed by using a statistics software package (STATA) to find dominant variables associated with knowledge (dummy variables) (Table 4). A dummy variable of a comprehensive knowledge-indicator 1, was 
categorised as high and low level based on median of the total score because it wasn't fit of normality distribution, while the indicators 2 to 5 were categorized into high (all answers are correct) and low (only one or two correct answers). This is in accordance with the cut-off off the measurement of comprehensive knowledge related to HIV $(12,14)$.

\section{RESULTS}

Women's education, occupation, residence, marital and economic status

Of the total 1,335 women surveyed, $67.85 \%$ $(n=922)$ had heard about HIV, and they were selected for further analysis. Of those 922 women, $67.85 \%$ had completed at least secondary school and approximately one half lived in rural areas. Seventy-five percent of women were married and had poor to middle economic status. The average age of respondents was 31 years old $(95 \% \mathrm{Cl} 30.44$ 31.22) (Table 2).

Table 2. Women's characteristics $(n=922)$

\begin{tabular}{llcc}
\hline \multicolumn{1}{c}{ Variables } & \multicolumn{1}{c}{ Category } & Total $(\mathbf{n = 9 2 2 )}$ & Percentage (\%) \\
\hline Education level & Primary & 227 & 24.59 \\
& Secondary & 546 & 59.21 \\
Occupation & Higher & 149 & 16.21 \\
\multirow{2}{*}{ Residence } & Yes & 532 & 57.74 \\
& No & 390 & 42.26 \\
Marital status & Urban & 425 & 46.10 \\
& Rural & 497 & 53.90 \\
& Not Married & 214 & 23.23 \\
Wealth index & Married & 687 & 74.53 \\
& Ever Married/living together & 21 & 2.24 \\
& Poorest & 268 & 29.08 \\
& Poorer & 204 & 22.07 \\
& Middle & 205 & 22.24 \\
& Richer & 139 & 15.08 \\
\hline Age, year (Mean, 95\% Cl) & Richest & 106 & 11.53 \\
\hline
\end{tabular}

Source: IDHS, 2012

Knowledge about HIV

Table 3 includes different types of HIV related knowledge, including how HIV can be prevented, transmitted, diagnosed and tested. Comprehensive knowledge of HIV includes four groups of knowledge, including on HIV prevention, transmission, HIV testing services, and mother to child transmission. In summary, more than half of the childbearing aged women in this study knew how to prevent HIV transmission (i.e. limiting sexual partners, using condoms and not sharing needles or syringe); and about mother to child HIV transmission during pregnancy, delivery and breastfeeding. Of concern, however, only about $10 \%$ of these women knew about existing HIV testing and VCT (Voluntary and Counselling Test) services.

HIV All determinants were associated with having heard of HIV among the women, except working status (Table 4). Marriage status and age were not associated significantly with having heard about
HIV (Table 5). Some stratification of knowledge related to HIV in this study includes the following parts.

\section{Comprehensive knowledge related to HIV}

Comprehensive knowledge of women comprises of women's understanding of how HIV can be transmitted, prevented, diagnosed and tested. About $55.22 \%$ of the 922 respondents had comprehensive knowledge of HIV (Table 2). Education, working status, and urban-rural residence were associated with having comprehensive knowledge after controlling possible confounders (Table 5).

\section{Knowledge of HIV prevention and transmission}

The majority of participants were aware of ways to prevent HIV transmission by limiting sexual partners and not sharing needles or syringes, and $52.7 \%$ knew that condoms could lower the risk of HIV transmission (Table 2). In the final logistic 
model, the women who had higher education, lived in urban areas and were employed had a better understanding of HIV prevention and transmission than those with lower education, lived in rural areas and were not employed (Table 5).

\section{Knowledge of HIV misconceptions}

Overall, the majority of the women had a low misconception about HIV transmission through a supernatural power and HIV person cannot be recognised through behaviour change. In addition, one to two in every four women believed that HIV could be transmitted by sharing food with HIVpositive persons from the same plate and they could identify someone as HIV positive from the person's physical appearance or health conditions (Table 2). Interestingly, about $70 \%$ of them believed that HIV could be transmitted through mosquito bites (Table 2). After controlling for the urban-rural residence and age, education level were the major social determinants associated with the women's HIV misconceptions (Table 5).

\section{Knowledge of mother-to-child transmission of HIV (MTCT)}

Up to $85 \%$ of the respondents knew that HIV can be transmitted during pregnancy, delivery/labour and breastfeeding (Table 4). Women with a higher education level and living in an urban area (AOR 3.2, $95 \% \mathrm{Cl} 1.8-5.5)$ had a higher degree of knowledge related to MTCT compared to those with a lower education level and living in a rural area after controlling their marital and employment status (Table 5).

\section{Knowledge of HIV testing}

Few women knew that HIV can be detected by doing a blood test. Less than $10 \%$ of them knew that free HIV testing was available through the Voluntary Counselling Testing (VCT) services (Table 3). Women who had higher education levels and those who were older (AOR 1.03, 95\% Cl 1.011.05) were more likely to know about HIV test and counselling (Table 5).

Table 3. Knowledge about HIV/AIDS

\begin{tabular}{lccc}
\hline Knowledge related to HIV & $\begin{array}{c}\text { Cate } \\
\text { gory }\end{array}$ & $\begin{array}{c}\text { Total } \\
\text { (n=922) }\end{array}$ & $\begin{array}{c}\text { Percenta } \\
\text { ge (\%) }\end{array}$ \\
\hline Comprehensive knowledge related to HIV & 514 & $55.22 \%$ \\
\hline Knowledge of HIV prevention (mean 4.6, SE 0.096) & & \\
Limiting partners to do sexual intercourse to reduce the risk of HIV & Yes & 655 & $72.6 \%$ \\
$\begin{array}{l}\text { A person becomes less likely to be infected with HIV/AIDS by using } \\
\text { condoms }\end{array}$ & Yes & 475 & $52.7 \%$ \\
A person infected with HIV/AIDS because of using shared syringe and & Yes & 823 & $91.3 \%$ \\
needle & & & \\
\hline Knowledge of HIV Transmission from mother to children (mean 4.8, & & \\
SE, 0.085) & Yes & 754 & $83.6 \%$ \\
HIV can be transmitted during pregnancy & Yes & 632 & $70.1 \%$ \\
HIV can be transmitted during a delivery/a labour & Yes & 720 & $79.8 \%$ \\
HIV can be transmitted through breastfeeding & & & \\
\hline Knowledge of HIV Test/Service (Mean 2.19, SE 0.02) & Yes & 94 & $10.5 \%$ \\
Knowing someone is infected with HIV/AIDS by a blood test & Yes & 71 & $7.9 \%$ \\
Having high self-awareness to do voluntarily HIV/AIDS test, followed by & & & \\
VCT, is expected to minimise the risk of HIV/AIDS & & 296 & $32.9 \%$ \\
\hline Misconception related to HIV (mean 7.9, SE 0.095) & Yes & 296 \\
Mosquito bites will not transmit HIV/AIDS & Yes & 416 & $46.1 \%$ \\
Someone could be infected with HIV-positive by eating with the same \\
plate with people with HIV/AIDS
\end{tabular}

Source: IDHS, 2012 


\section{DISCUSSION}

Women of childbearing age are considered as a 'bridge' in the HIV epidemic from low-risk to highrisk groups such as injecting drug users, men having sex with men, female sex workers, and transgender in Indonesia( ${ }^{(4)}$. Hence, the enhancement of HIV knowledge related to HIV prevention, transmission and testing is urgently needed among women of childbearing age in Indonesia. Compared with two previous national surveys in Indonesia(15, 22), this study showed a significant increase of HIV comprehensive knowledge in women of childbearing age by about fivefold. The last two surveys in 2007 and 2013 respectively, showed only $9 \%$ and $11 \%$ of women respectively had HIV comprehensive knowledge. In this study more than $50 \%$ women had acquired HIV comprehensive knowledge. Of note however, different cut-off points of categorisation of a comprehensive level of knowledge might lead to these differences.

Although an increased knowledge of MTCT was found in this study compared with the previous surveys ${ }^{(15,22)}$, only one in nine women knew about free HIV testing and counselling services. Health services need to be made more accessible to women, particularly rural women. Half of the women knew about condom use to prevent HIV, but this finding may suggest inadequate condom use in childbearing age women in South Sumatra. An absence of a government intervention to halt MTCT would increase the transmission of HIV by as much as $15-50 \%{ }^{(23)}$. In addition, a newly HIVinfected women is more likely to transmit HIV to her baby during pregnancy or post-partum ${ }^{(24,25)}$. Therefore, quick implementation of Indonesia's Ministry of Health Regulation Number 43 (2016) that recommends that people with at least one of the risk factors of HIV become involved in relevant treatments like VCT and Prevention of Mother-toChild of HIV Transmission (PMTCT) services, including HIV screening among pregnant women in all provinces in Indonesia, either with low- or high- prevalence provinces (26). We have to stop assuming that women, particularly married women-mothers and wives- or Ibu rumah tangga are a low-risk (4-6, 27-30).

Of concern, women's misconception of HIV is still rampant. For instance, more than half of the women still believe that HIV can be transmitted by mosquito's bites and sharing foods in the same plate with HIV-positive persons. While we have not discussed this in the analysis, we note here that one of nine women believe that HIV can be transmitted through supernatural power. Further research is warranted on this topic. Similar findings were reported in IDHS 2012 in 33 provinces, three out of 10 women think that someone can get HIV from witchcraft ${ }^{(14)}$. A similar finding was also recently reported in similar national surveys conducted in Bangladesh and Cambodia ${ }^{(19,31)}$. A study by Yaya and colleagues
(2016) also found that about one fifth women in Bangladesh believed that HIV could be caused by witchcraft or supernatural powers and about half of them believed that HIV can be transmitted by mosquito bites or sharing food from the same plate with HIV-positive persons ${ }^{(19)}$. A Cambodian Demographic and Health Survey in 2005 found that compared to their peers in Bangladesh, Cambodian women have a slightly better understanding about HIV misconceptions $(19,31)$. Nevertheless, this study found that women in South Sumatra have better understanding on HIV knowledge that every healthy people can be affected HIV and physical changes cannot help to recognise HIV-positive person in wider population, similar to national level, Indonesia ${ }^{(14)}$.

Our findings strongly suggest that, after controlling for possible confounders, education and urban-rural residence are associated with having comprehensive HIV knowledge (Table 5). This finding concurs with other findings reported by Angkasawati (2007) ${ }^{(2)}$, Yaya et al. (2016) ${ }^{(19)}$ and Hong et al. ${ }^{(31)}$. Unlike that reported by Yaya and colleagues, whereby being married was associated with having increased knowledge, our study did not support such association. In Iswanto's study $(2011)^{(13)}$, the education level of both women and their husbands were related to the level of HIV knowledge. Men tend to have better HIV related knowledge compared to women $(32,33)$. However, Yaya $(2016)^{(19)}$ found that women's status within the household also plays a significant role in HIV knowledge acquisition. Female heads of households in Bangladesh had a better understanding of HIV compared to male heads of households) ${ }^{(19)}$. The interplay of a woman's education, marital status, and being the head of a household in explaining HIV knowledge acquisition, warrant further studies.

Our findings concur other studies conducted with Indonesian, Palestinian, Tajik, and Cambodian women $(14,18,20,31)$, that women who had a higher education were more likely to have good HIV related knowledge. Women living in urban area had a better understanding on HIV prevention and MTCT. Interestingly, while other studies, such as those of Husseini A and Abu Rehileh (2007) who worked with Palestinian women and Zainiddinov and Habibov (2016) who worked with Tajik women, found age was an important determinant in understanding HIV prevention and transmission ${ }^{(18,20)}$, in our study, age tended to be a confounding factor for HIV knowledge acquisition. In our study older women were more likely to know about HIV testing (see Table 5). Lack of controlling for confounders might contribute to differences in results found between others' and our analysis. 
Table 4 Bivariate analysis of determinants of knowledge among women of childbearing age in South Sumatra, Indonesia

\begin{tabular}{|c|c|c|c|c|c|c|c|}
\hline \multirow{2}{*}{$\begin{array}{l}\text { Category Variables } \\
\qquad(n=922)\end{array}$} & & \multicolumn{6}{|c|}{ Knowledge about HIV/AIDS } \\
\hline & & $\begin{array}{c}\text { Ever heard about } \\
\text { HIV }\end{array}$ & $\begin{array}{l}\text { Indicato } \\
\text { r } 1\end{array}$ & Indicator 2 & Indicator 3 & Indicator 4 & Indicator 5 \\
\hline & & OR $(95 \% \mathrm{Cl})$ & $\begin{array}{l}\text { OR (95 } \\
\% \mathrm{Cl})\end{array}$ & $M D(S E)$ & $M D(S E)$ & $M D(S E)$ & $M D(S E)$ \\
\hline \multirow[t]{2}{*}{$\begin{array}{l}\text { Education level } \\
\text { (Primary as ref) }\end{array}$} & Secondary & $5.6(4.2-7.4)^{* * *}$ & $\begin{array}{l}1.5(1.1- \\
2.2)^{* * *}\end{array}$ & $0.7(0.2)^{* * *}$ & $0.7(0.1)^{* * *}$ & $0.2(0.1)^{*}$ & $0.1(0.02)^{* *}$ \\
\hline & Higher & $97.8(23.4-409)^{* * *}$ & $\begin{array}{l}3.8(2.3- \\
6.2)^{* * *}\end{array}$ & $1.3(0.1)^{* * *}$ & $1.6(0.2)^{* * *}$ & $0.9(0.1)^{* * *}$ & $0.3(0.1)^{* * *}$ \\
\hline $\begin{array}{c}\text { Working status } \\
\text { (Unemployed as ref) }\end{array}$ & Yes & $(0.7-1.3)^{*}$ & $\begin{array}{l}1.5(1.1- \\
2.1)^{* * *}\end{array}$ & $0.3(0.1)^{* *}$ & $0.3(0.1)^{* *}$ & $0.2(0.1)^{*}$ & $0.05(0.03)^{*}$ \\
\hline Residence (Rural as ref) & Urban & $5.1(3.2-8.1)^{* * *}$ & $\begin{array}{l}1.7(1.2- \\
2.4)^{* * *}\end{array}$ & $0.7(0.1)^{* * *}$ & $0.8(0.1)^{* * *}$ & $0.6(0.1)^{* * *}$ & $0.1(0.03)^{* *}$ \\
\hline \multirow[t]{2}{*}{$\begin{array}{l}\text { Marital status (ever married/living together as } \\
\text { ref) }\end{array}$} & $\begin{array}{l}\text { Not } \\
\text { married }\end{array}$ & $2.9(1.3-6.5)^{* *}$ & $\begin{array}{l}0.7(0.3- \\
1.9)^{*}\end{array}$ & $0.01(0.1)^{*}$ & $0.2(0.1)^{*}$ & $-0.5(0.1)^{*}$ & $-0.1(0.03)^{*}$ \\
\hline & Married & $1.5(0.7-3.0)^{*}$ & $\begin{array}{l}0.9(0.3- \\
2.3)^{*}\end{array}$ & $0.1(0.1)^{*}$ & $-0.2(0.1)^{*}$ & $-0.2(0.1)^{*}$ & $-0.1(0.02)^{*}$ \\
\hline \multirow[t]{4}{*}{ Wealth index (Richest as ref) } & Poorest & $12.9(7.9-21.0)^{* * *}$ & $\begin{array}{l}1.5(0.9- \\
2.5)^{*}\end{array}$ & $0.2(0.1)^{*}$ & $0.4(0.1)^{*}$ & $0.1(0.1)^{*}$ & $0.1(0.03)^{*}$ \\
\hline & Poorer & $3.6(2.5-5.0) * * *$ & $\begin{array}{l}1.4(0.8- \\
2.4)^{*}\end{array}$ & $-0.003(0.1)^{*}$ & $0.2(0.2)^{*}$ & $0.1(0.2)^{*}$ & $0.03(0.04)^{*}$ \\
\hline & Middle & $3.7(2.6-5.3) * * *$ & $\begin{array}{l}1.2(0.7- \\
1.9)^{*}\end{array}$ & $0.041(0.1)^{*}$ & $0.2(0.1)^{*}$ & $0.4(0.1) *$ & $0.05(0.04)^{*}$ \\
\hline & Richer & $1.8(1.2-2.5) * * *$ & $\begin{array}{l}1.2(0.7- \\
2.1)^{*}\end{array}$ & $0.08(0.2)^{*}$ & $0.1(0.2)^{*}$ & $0.2(0.2) *$ & $0.08(0.04) *$ \\
\hline $\begin{array}{l}\text { Age of reproductive women (mean difference, } \\
\qquad \mathrm{SE} \text { ) }\end{array}$ & & $\begin{array}{c}-0.02(- \\
0.03,0.005)^{* * *}\end{array}$ & $\begin{array}{l}0.01 \\
(-0.01 \\
0.02)^{*}\end{array}$ & $\begin{array}{l}0.001 \\
(-0.01)- \\
0.01)^{*}\end{array}$ & $\begin{array}{l}-0.003 \\
(-0.02)- \\
0.01))^{*}\end{array}$ & $\begin{array}{l}0.01 \\
(0.001- \\
0.03)^{* *}\end{array}$ & $\begin{array}{l}0.003 \\
(-0.001)- \\
0.007))^{*}\end{array}$ \\
\hline
\end{tabular}

\section{Source: IDHS, 2012}

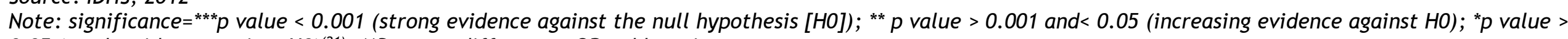
0.05 (weak evidence against $H 0$ ) ${ }^{(21)} ; M D=$ mean difference; $O R=o d d s$ ratio

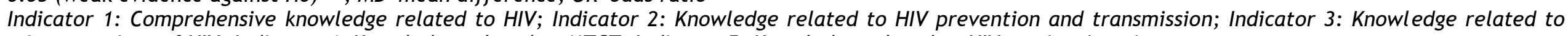
misconceptions of HIV; Indicator 4: Knowledge related to MTCT; Indicator 5: Knowledge related to HIV services/testing 
Table 5 Logistic Regression Model for social determinants of HIV knowledge among women of childbearing age in South Sumatra, Indonesia

\begin{tabular}{|c|c|c|c|c|c|c|c|}
\hline \multirow{2}{*}{$\begin{array}{l}\text { Category Variables } \\
\qquad(\mathrm{n}=922)\end{array}$} & & \multicolumn{6}{|c|}{ Knowledge about HIV/AIDS } \\
\hline & & $\begin{array}{c}\text { Ever heard about } \\
\text { HIV }\end{array}$ & $\begin{array}{l}\text { Indicat } \\
\text { or } 1\end{array}$ & Indicator 2 & Indicator 3 & Indicator 4 & Indicator 5 \\
\hline & & AOR $(95 \% \mathrm{Cl})$ & $\begin{array}{c}\text { AOR } \\
(95 \% \\
C l)\end{array}$ & AOR $(95 \% \mathrm{Cl})$ & AOR $(95 \% \mathrm{Cl})$ & $\begin{array}{l}\text { AOR }(95 \% \\
\text { CI) }\end{array}$ & AOR $(95 \% \mathrm{Cl})$ \\
\hline \multirow[t]{2}{*}{$\begin{array}{l}\text { Education level } \\
\text { (Primary as ref) }\end{array}$} & Secondary & $4.8(3.4-6.7)^{* * *}$ & $\begin{array}{l}1.6(1.1- \\
2.3)^{* *}\end{array}$ & $2.5(1.3-4.8)^{* * *}$ & $1.7(0.9-3.4)^{*}$ & $\begin{array}{l}1.4(0.9- \\
2.3)^{*}\end{array}$ & $1.9(1.0-3.8)^{*}$ \\
\hline & Higher & $72.6(17.3-304.6)^{* * *}$ & $\begin{array}{l}3.7(2.2- \\
6.2)^{* * *}\end{array}$ & $\begin{array}{c}16.6(1.8- \\
153.9)^{* *}\end{array}$ & $5.1(1.1-23.1)^{* *}$ & $\begin{array}{l}11.1(3.3- \\
36.9)^{* * *}\end{array}$ & $5.7(2.8-11.4)^{* * *}$ \\
\hline $\begin{array}{l}\text { Working status } \\
\text { (Unemployed as ref) }\end{array}$ & Yes & - & $\begin{array}{l}1.5(1- \\
2.1)^{*}\end{array}$ & - & - & $\begin{array}{l}1.4(0.9- \\
2.1)^{*}\end{array}$ & - \\
\hline Residence (Rural as ref) & Urban & $3.2(2.1-5.1)^{* * *}$ & - & $\begin{array}{l}3.36(1.8- \\
6.2)^{* * *}\end{array}$ & $1.4(0.7-2.8)^{*}$ & $\begin{array}{l}3.2(1.8- \\
5.5)^{* * *}\end{array}$ & $1.6(1.0-2.5)^{*}$ \\
\hline \multirow[t]{2}{*}{$\begin{array}{l}\text { Marital status (ever married/living together } \\
\text { as ref) }\end{array}$} & $\begin{array}{c}\text { Not } \\
\text { married }\end{array}$ & $0.8(0.2-2.4)^{*}$ & $\begin{array}{l}0.5(0.2- \\
1.5)^{*}\end{array}$ & $0.9(0.2-4.1)^{*}$ & - & $\begin{array}{c}0.4(0.1- \\
1.8)^{*}\end{array}$ & - \\
\hline & Married & $1.3(0.5-3.7)^{*}$ & $\begin{array}{l}0.8(0.3- \\
2.3)^{*}\end{array}$ & $1.9(0.5-7.7)^{*}$ & - & $\begin{array}{l}0.7(0.1- \\
3 .)^{*}\end{array}$ & - \\
\hline \multirow[t]{4}{*}{$\begin{array}{l}\text { Wealth index } \\
\text { (Richest as ref) }\end{array}$} & Poorest & $12.5(7.6-20.6)^{* * *}$ & - & - & - & - & - \\
\hline & Poorer & $3.7(2.5-5.4)^{* * *}$ & - & - & - & - & - \\
\hline & Middle & $3.7(2.5-5.3)^{* * *}$ & - & - & - & - & - \\
\hline & Richer & $1.7(1.1-2.7)^{* * *}$ & - & - & - & - & - \\
\hline $\begin{array}{l}\text { Age of reproductive women (mean } \\
\text { difference, SE) }\end{array}$ & & $0.99(0.97-1.01)^{*}$ & $\begin{array}{l}0.9(0.9- \\
1)^{*}\end{array}$ & - & $\begin{array}{l}0.98(0.94- \\
1.02)^{*}\end{array}$ & - & $\begin{array}{c}1.03(1.01- \\
1.05)^{* *}\end{array}$ \\
\hline
\end{tabular}

ifference, SE)

$1)^{*}$

$1.02)^{*}$

$1.05)^{* *}$

Note: ${ }^{* * *} p$ value $<0.001 ;{ }^{* *} p$ value $>0.001$ and $<0.05 ;{ }^{*} p$ value $>=0.05 ;$ AOR=Adjusted Odds Ratio; Cl=Confidence Interval

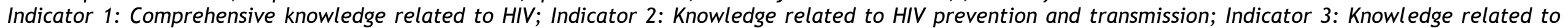
misconceptions of HIV; Indicator 4: Knowledge related to MTCT; Indicator 5: Knowledge related to HIV services/testing 


\section{CONCLUSION}

This article has shown that of 922 respondents who have ever heard about HIV, 55.22\% $(n=514)$ have HIV comprehensive knowledge in South Sumatra with low-prevalence province in Indonesia. Of the women who have comprehensive knowledge, majority of the women do not know that they can get free HIV tests. We show that education and type of residence were positively associated with comprehensive HIV knowledge. After stratifying knowledge related to HIV, higher education levels were shown to be a dominant determinant associated with all types of HIV knowledge. Type of residence did not correlate with HIV knowledge.

To reach more women in rural areas, as well as low-educated women, health services for mothers and children should be comprehensively integrated with HIV information services (prevention, transmission, and services) aimed at women of childbearing age and pregnant women in an early stage in order to mitigate the HIV transmission. Promoting detailed information related to HIV, including HIV testing, is urgently needed in formal education for women in rural areas and low-prevalence provinces in Indonesia. Finally, ibu rumah tangga and employed and unemployed women need to stop assuming that they are low risk of contracting HIV and need to enhance their HIV literacy from offline or online platforms.

\section{LIMITATIONS}

This study presented data from South Sumatra, one province of Indonesia. Further study is needed to obtain a comprehensive understanding of general versus specific social determinants of women's HIV vulnerability within high- versus lowprevalence provinces in Indonesia. Furthermore, determinants of this study are dependent on the availability of variables in the IDHS-2012, therefore there are limits. Potential limitations of secondary data bases are selection and measurement bias, confounding by indication, unmeasured or residual confounding and outcome misclassification, which may result in erroneous conclusion (34). Further research on the impact of supernatural beliefs and qualitative approach on understanding women's knowledge and perception about HIV is also needed.

\section{Declaration}

Consent to publish

None declared

Availability of data and materials

None declared

Competing interests

The authors declare that they have no

competing interests

\section{Funding}

NA received scholarship from the New Zealand Government, Ministry of Foreign Affair and Trade (MFAT)-New Zealand Asean Scholarship for her Ph.D. NA also received research funding from Auckland University of Technology, Auckland and Universitas Sriwijaya, Indonesia.

\section{Authors' Contributions}

The idea of developing idea of research and wrote the first draft of the manuscript by NA, IPS and TNK. IPS extracted, coded, and interpreted data. SA and SGD assisted with the manuscript and provided quantitative and English writing expertise.

All authors read and approved the final manuscript.

\section{Acknowledgements}

We would like to thank to New Zealand scholarship (NZAid) to fund the first author for her Ph.D in AUT. We would acknowledge of school of public health, librarians, and learning advisors in Auckland University of Technology, the rector and dean of Public Health Faculty of Sriwijaya University and staffs to support NA.

\section{REFERENCES}

1. MoH. Report of Situation Analysis of HIVAIDS in 2017. Jakarta: The Indonesian Ministry of Health; 2018.

2. MoH. National Action Plan of Prevention of Mother to Child Transmission (PMTCT) program, Indonesia 2013-2017. Jakarta: Ministry of Health-Indonesia; 2013.

3. Muhaimin T, Besral. HIV Prevalence among pregnant mothers in eight capital cities in Indonesia, year of 2003-2010 MAKARA KESEHATAN. 2011; Vol. 15(2):93-100.

4. Rahmalia A, Wisaksana R, Meijerink $\mathrm{H}$, Indrati AR, Alisjahbana B, Roeleveld N, et al. Women with HIV in Indonesia: are they bridging a concentrated epidemic to the wider community? BMC research notes. 2015;8(1):1.

5. Imelda JD. Disease interpretations and response among HIV-positive mothers. Antropologi Indonesia. 2015:4-16.

6. Damar AP, du Plessis G. Coping versus grieving in a 'deathaccepting'society: AIDS-bereaved women living with HIV in Indonesia. Journal of Asian and African studies. 2010;45(4):424-31. 
7. Adimora AA, Schoenbach VJ. Social Determinants of Sexual Networks, Partnership Formation, and Sexually Transmitted Infections. In: Aral SO, Fenton KA, Lipshutz JA, editors. The new public health and STD/HIV prevention: personal, public and health systems approaches. New York: Springer Science \& Business Media; 2012. p. 13-29.

8. Baral S, Logie $\mathrm{CH}$, Grosso A, Wirtz AL, Beyrer C. Modified social ecological model: a tool to guide the assessment of the risks and risk contexts of HIV epidemics. BMC public health. 2013;13(1):1.

9. Davidson A. Social Determinants of Health, a Comparative Study. Canada: Oxford; 2015.

10. World Health Organization. Social determinants of health Geneva: WHO; 2012 [Available from: http: / / www. who.int/gender-equityrights/understanding/sdhdefinition/en/.

11. Higgins JA, Hoffman S, Dworkin SL. Rethinking gender, heterosexual men, and women's vulnerability to HIV/AIDS. American Journal of Public Health. 2010;100(3):435-45.

12. Angkasawati TJ, Arifin A. Comprehensive knowledge and attitude related to HIV among childbearing age women in Indonesia, 2007. Bulletin of Health System Research. 2010;13(2).

13. Iswanto L. Knowledge related to HIV among Indonesian women Populasi. 2011;22(1):68-75.

14. Pradnyani PE, Arief Wibowo M. The Effects of Socio-demographic Characteristics on Indonesian Women's Knowledge of HIV/AIDS: A Cross-sectional Study. Journal of Preventive Medicine and Public Health. 2019;52(2):109.

15. MoH. National Report-Basic Health Survey (RISKESDAS) 2013. Jakarta: National Institute of Health Research and Development, MOH; 2013.

16. Statistics Indonesia, National Population and Family Planning Board, $\mathrm{MOH}$, Measure DHS ICF International. Indonesian
Demographic Health Survey-2012. Jakarta: Statistics Indonesia; 2013.

17. Mahendradhata $\mathrm{Y}$, Trisnantoro L, Listyadewi S, Soewondo P, Marthias $\mathrm{T}$, Harimurti $\mathrm{P}$, et al. The Republic of Indonesia Health System Review. Geneva: WHO; 2017. Available from: https://apps.who.int/iris/bitstream /handle/10665/254716/97892902251 64-

eng.pdf?sequence=1\&isAllowed=y.

18. Husseini A, Abu-Rmeileh NM. HIV/AIDS-related knowledge and attitudes of Palestinian women in the Occupied Palestinian Territory. American journal of health behavior. 2007;31(3):323-34.

19. Yaya S, Bishwajit G, Danhoundo G, Shah V, Ekholuenetale M. Trends and determinants of HIV/AIDS knowledge among women in Bangladesh. BMC public health. 2016;16(1):812.

20. Zainiddinov H, Habibov N. Trends and predictors of knowledge about HIV/AIDS and its prevention and transmission methods among women in Tajikistan. The European Journal of Public Health. 2016;26(6):1075-9.

21. Kirkwood BR, Sterne JA. Essential medical statistics. Massachussetts: John Wiley \& Sons; 2007.

22. Statistics Indonesia. Indonesian Demographic Health Survey-2007. Jakarta: Statistics Indonesia; 2007.

23. De Cock KM, Fowler MG, Mercier E, de Vincenzi I, Saba J, Hoff E, et al. Prevention of mother-to-child HIV transmission in resource-poor countries: translating research into policy and practice. Jama. 2000;283(9):1175-82.

24. Thorne C. Newly infected mothers are more likely pass HIV on to babies. February 2014, [Internet]. 2014. Available from: https: / / theconversation.com/newlyinfected-mothers-are-more-likelyto-pass-hiv-on-to-babies-23578.

25. Drake AL, Wagner A, Richardson B, John-Stewart G. Incident HIV during pregnancy and postpartum and risk of mother-to-child HIV transmission: a systematic review and meta-analysis. PLoS medicine. 2014;11(2):e1001608. 
26. Regulation of Basic Standard Services in Health number 43, No 43 in 2016 (2016).

27. MoH. Transmission mode of HIV vulnerabile population, homemaker and children in getting HIV in Indonesia. In: Program TPoMtCToHP, editor. Sakti, Gita Maya, Orientasi Pencegahan Penularan HIV dari Ibu ke Anak (PPIA) Jakarta, 24-27 November 2015. Jakarta: The Directorate of Maternal Health, Ministry of Health, Indonesia; 2012.

28. Najmah, Andajani S, Davies SG. HIVpositive mothers left behind: INSIDER INDONESIA; 2017 [Available from: https: / / www.insideindonesia.org/hi $v$-positive-mothers-left-behind.

29. Najmah. Enabling HIV-positive Indonesian women to access Prevention of Mother-to-Child Transmission of HIV services (in press). Auckland: Auckland University of Technology; 2019.

30. Najmah, Davies SG, Andajani S. Every Indonesian women is at risk of HIV: The spider's web of women vulnerability to HIV: A complex story of Transmission A writing workshop with SOMAA (Society of Medical Antropology in Aoetea), AUT, and University of Auckland, ; Auckland: Auckland University of Technology; 2018.

31. Hong R, Chhea V. Changes in HIVrelated knowledge, behaviors, and sexual practices among Cambodian women from 2000 to 2005 . Journal of Women's Health. 2009;18(8):1281-5.

32. Oktarina O, Hanafi F, Budisuari MA. Assocation between respondents' charactersitics, residence area and knowledge and attitude towardss HIV-AIDS in Indonesian community Healty System Research Buletin (Buletin Penelitian Sistem Kesehatan). 2009;12(4).

33. Sudikno S, Simanungkalit B, Siswanto S. Knowledge related to HIV-AIDs among teenagers in Indonesia (Data analysis of National Basic Health Survey 2010). Jurnal Kesehatan Reproduksi. 2011;1(3 Agt):145-54.

34. Prada-Ramallal G, Takkouche B, Figueiras A. Bias in pharmacoepidemiologic studies using secondary health care databases: a scoping review. BMC medical research methodology. 